\title{
Matemática, meio ambiente e arte: transformando lixo em luxo!
}

\section{Matemáticas, medio ambiente y arte: jtransformando basura em lujo!}

\author{
Bruna Silva dos Santos Moreira \\ Secretaria Estadual de Educação do Rio de Janeiro (SEEDUC-RJ), Maricá, RJ, Brasil \\ https://orcid.org/0000-0003-4879-8528, supramor@yahoo.com.br
}

\author{
Rosa María García Márquez \\ Universidade Estadual do Rio de Janeiro (UERJ), Faculdade de Formação de Professores \\ Departamento de Matemática, São Gonçalo, RJ, Brasil \\ https://orcid.org/0000-0003-3465-569X, rosagmarquez@yahoo.com.br
}

\author{
Universidade Estadual do Rio de Janeiro (UERJ), Faculdade de Formação de Professores \\ Departamento de Matemática, São Gonçalo, RJ, Brasil \\ https://orcid.org/0000-0002-1015-6311, icaraujo@ipri.ueri.br
}

\begin{abstract}
Informações do Artigo
Como citar este artigo

MOREIRA, Bruna Silva dos Santos;

MÁRQUEZ, Rosa María García; ARAÚJO,

Jorge Corrêa de. Matemática, meio ambiente

e arte: transformando lixo em luxo!. REMAT:

Revista Eletrônica da Matemática, Bento

Gonçalves, RS, v. 6, n. 1, p. 01-18, jan. 2020

DOI:

https://doi.org/10.35819/remat2020v6i1id3513
\end{abstract}

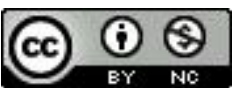

\section{Histórico do Artigo}

Submissão: 29 de junho de 2019.

\section{Palavras-chave}

Ensino de Matemática

Arte

Meio Ambiente

Lixo
Aceite: 12 de novembro de 2019.

\section{Resumo}

Devido ao crescente aumento da população e, consequentemente, do uso exagerado dos recursos naturais e da produção industrial, existe atualmente uma constante preocupação de organizações governamentais e não governamentais com a preservação do meio ambiente e com a qualidade de vida das futuras gerações. Neste sentido, é fundamental envolver o jovem estudante com as preocupações ambientais trabalhando de forma contextualizada e relacionando o meio ambiente aos conteúdos desenvolvidos em sala de aula, possibilitando a interação entre diferentes ciências, em especial a Matemática, por meio da interdisciplinaridade. O presente trabalho apresenta um relato de experiência realizada com uma turma piloto de oitavo ano do Ensino Fundamental, em uma escola na cidade de Maricá, no Estado do Rio de Janeiro. Foram abordados tópicos de Matemática com ênfase em estatística, de modo a quantificar a produção de lixo ambiental de uma amostra recolhida dentro do perímetro urbano da cidade. Durante este processo, foram propostas atividades interdisciplinares de modo a relacionálas com as etapas de produção e a destinação do lixo ambiental. Tal experiência foi vivenciada em diferentes momentos, entre os quais se pode destacar: palestra, uso da sala de recursos, oficina de Arte e Matemática, bem como produção textual. A interação e a colaboração em cada etapa das atividades realizadas pela turma mostram que a interdisciplinaridade é uma grande aliada para uma aprendizagem significativa, ou seja, colabora para a formação de alunos críticos, reflexivos e criativos, capazes de entenderem a importância da Matemática como uma aliada na preservação ambiental.

\section{Resumen}

Palabras clave

Enseñanza de Matemáticas

Arte

Medio Ambiente

Basura
Debido al creciente aumento de la población y, consecuentemente del uso exagerado de los recursos naturales y de la producción industrial, existe actualmente una constante preocupación de organizaciones gubernamentales y no gubernamentales con la preservación del medio ambiente y con la calidad de vida de las futuras generaciones. En este sentido, es fundamental involucrar al joven estudiante con las preocupaciones ambientales, trabajando de forma contextualizada y relacionando el medio ambiente a los contenidos desarrollados en el aula, posibilitando la interacción entre diferentes ciencias, en especial la Matemática 


\begin{abstract}
a través de la interdisciplinariedad. Este trabajo presenta un relato de experiencia realizada con una clase piloto de octavo grado, en una escuela en la ciudad de Maricá en el estado de Rio de Janeiro. Fueron abordados temas matemáticos, con énfasis en estadística, para cuantificar la producción de residuos ambientales de una muestra recolectada dentro del perímetro urbano de la ciudad. Durante este proceso, se propusieron actividades interdisciplinarias para relacionarlas con las etapas de producción y la eliminación de los desechos ambientales. Esta experiencia fue vivenciada en diferentes momentos, entre los cuales se puede destacar: charla, sala de recursos, sala de informática, taller de Arte y Matemática, así como producción textual. La interacción y colaboración en cada etapa de las actividades realizadas por la clase, muestran que la interdisciplinaridad es una gran aliada para un aprendizaje significativo, o sea, contribuye en la formación de alumnos críticos, reflexivos y creativos, capaces de entender la importancia de las Matemáticas como uma aliada a la preservación ambiental.
\end{abstract}

\title{
1. Introdução
}

O crescimento populacional mundial a taxas geométricas e o consumismo exagerado desta mesma população pressionam o meio ambiente com a ampliação das áreas de plantio, bem como com o aumento da produção industrial para a produção de bens decorrente do consumo. Estes problemas foram abordados pela ONU, na Suécia, em 1972, durante a Conferência das Nações Unidas sobre o Meio Ambiente Humano, a qual deu origem à Organização para Cooperação e Desenvolvimento Econômico (OCDE). Paralelamente a este evento, surgiram diversas instituições não governamentais como a Greenpeace.

O crescimento populacional mundial observado a partir do meado do século $X X$ até início do século $\mathrm{XXI}$, aliado ao ritmo crescente de produção de alimentos e bens materiais modificáveis de baixo custo nesse mesmo período, permitiu à grande maioria dessa mesma população, o consumo quase irrestrito desses bens de produção. Em decorrência desse "consumismo", problemas ambientais em larga escala começaram a ocorrer como, por exemplo, a poluição em lagoas, rios e oceanos.

Neste sentido, cabe aos educadores proporem uma nova pedagogia de educação que contemple a discussão sobre o meio ambiente e suas formas de manejo. Conforme Tajra (2007, p. 12), "cabe principalmente à escola e aos educadores junto aos familiares prepararem cidadãos conscientes, criativos e intelectualmente capazes para viverem em um mundo cada vez mais competitivo e em completa transformação".

Por isso, cabe, em especial, aos professores despertarem a consciência ecológica dos alunos, motivando-os a se ocuparem com as questões ambientais, trabalhando-as de forma contextualizada de modo a possibilitar a interação entre as diferentes ciências, nas quais a Matemática é essencial.

De acordo com os Parâmetros Curriculares Nacionais (PCN)

A compreensão das questões ambientais pressupõe um trabalho interdisciplinar em que a Matemática está inserida. A quantificação de aspectos envolvidos em 
problemas ambientais favorece uma visão mais clara deles, ajudando na tomada de decisões e permitindo intervenções necessárias (reciclagem e reaproveitamento de materiais, por exemplo). (BRASIL, 1998, p. 38).

O objetivo desse trabalho é utilizar atividades interdisciplinares envolvendo, em especial, a Matemática, de modo a relacioná-las com as etapas da produção e a destinação, em particular, do lixo ambiental, de modo a conscientizar os discentes da importância do tema tratado e alertandoos de que todos nós somos impactados por atitudes negativas junto ao meio ambiente.

Segundo Siqueira (2001), a interdisciplinaridade pode ser caracterizada como nível em que a colaboração entre as disciplinas conduz a interações propriamente ditas, de tal forma que, no final do processo interativo, cada disciplina saia enriquecida. Desta forma, a escolha de um projeto interdisciplinar com o objetivo de produzir alertas quanto à necessidade dos cuidados com o meio ambiente envolveu as disciplinas de Matemática, Ciências, Artes e Português.

\section{Relato de Experiência}

A experiência que aqui será relatada utilizou uma turma de $8^{\circ}$ ano localizada no município de Maricá - Rio de Janeiro. Houve a participação dos 35 alunos que integram a turma, com idades entre doze e quatorze anos, além da valiosa colaboração dos professores: Edson Cavalcanti (Português, SEEDUC, RJ'1), Elisângela da Rocha (Artes, $\mathrm{PMRO}^{2}$ ) e Fábio Araújo (Biologia, UERJ ${ }^{3}$ ). Tal experiência foi dividida em seis atividades: palestra, sala de recursos, sala de informática, oficina de Arte e Matemática, atividade matemática e produção textual. Estas atividades foram realizadas em um período de cinco dias, sempre pela manhã e com duração máxima de duas horas diárias.

Os métodos de pesquisa selecionados para compor este trabalho foram a pesquisa-ação e o estudo de caso descritivo. Segundo Elliot (1997), a pesquisa-ação permite superar as lacunas existentes entre a pesquisa educativa e a prática docente. Com os resultados desta prática, são ampliadas as capacidades de compreensão dos professores para o fenômeno de interesse. Segundo Ponte (1994, p. 55), os estudos de caso "podem ser fundamentalmente descritivos, tendo como propósito essencial descrever, isto é, dizer simplesmente "como é' o caso em apreço". Nesse sentido, esta pesquisa aqui desenvolvida tem caráter tanto quantitativo como qualitativo, pois reúne dados que podem ser interpretados de forma numérica, dando-lhes significado qualitativo.

\subsection{Palestra com organizadores do Projeto "Praia Limpa é a minha Praia"}

Para abertura das atividades, foi convidada a equipe do Projeto "Praia Limpa é a minha Praia" (ARAÚJO et al., 2014) para a realização de uma palestra que teve por objetivo principal

\footnotetext{
1 SEEDUC, RJ: Secretaria Estadual de Educação do Rio de Janeiro.

2 PMRO: Prefeitura Municipal de Rio das Ostras.

${ }^{3}$ UERJ: Universidade Estadual do Rio de Janeiro.
} 
estimular a mudança de hábitos e atitudes dos alunos em relação à conservação do meio ambiente, particularmente em praias. A Figura 1 mostra a palestra proferida pelo professor Fábio Viera de Araújo do Projeto "Praia Limpa é a minha Praia".

Figura 1 - Palestra do Projeto "Praia Limpa é a minha Praia".

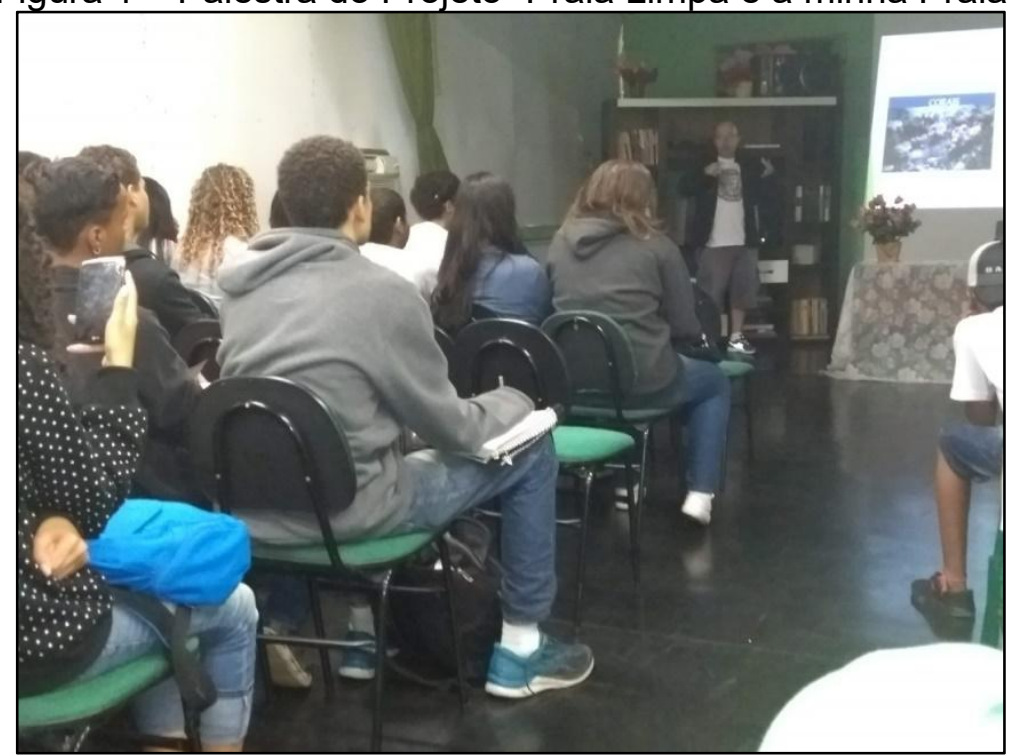

Fonte: Arquivo pessoal dos autores (2018).

Este momento, com duração de aproximadamente uma hora, proporcionou um contato especial sobre o assunto, pois a abordagem do tema por meio de um profissional da área tornou mais impactante a problemática sobre preservação do meio ambiente. Foi forte o impacto causado nos participantes do encontro, como é relatado a seguir.

As informações sobre microplástico (fragmentos de plástico com medidas de 1 a $5 \mathrm{~mm}$ ), conforme mostra a Figura 2, e as alterações ambientais causadas por resíduos de plástico foram os aspectos que mais causaram perplexidade na plateia, pois os participantes não imaginavam que atitudes habituais e aparentemente inofensivas, poderiam causar efeitos tão perniciosos ao meio ambiente.

Figura 2 - Microesferas de polietileno em esfoliantes e sabonetes.

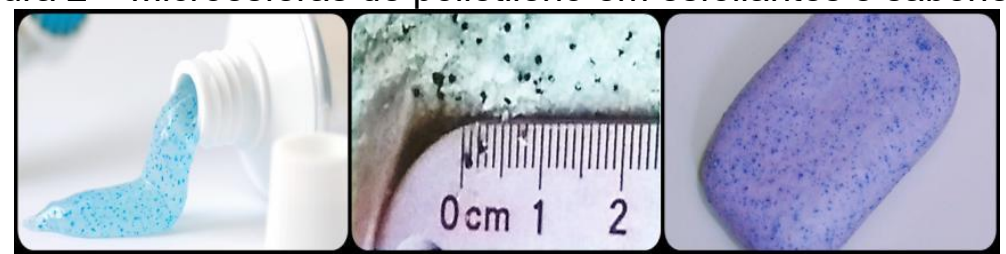

Fonte: Elaboração dos autores (2018).

Durante o encontro, houve contestações um tanto curiosas, como, por exemplo, em determinado momento o palestrante, professor Araújo, sugeriu alguns hábitos ecologicamente corretos, tais como: utilizar sacolas retornáveis, não usar cremes dentais e sabonetes que possuam micro plástico em sua composição, recusar produtos descartáveis em geral, bem como outros procedimentos simples e bem conhecidos. Em seguida, um participante pediu a palavra e perguntou: "O que adianta eu fazer isso, se as outras pessoas não vão fazer o mesmo?". O 
palestrante explicou calmamente que cada um deveria fazer a sua parte e que o planeta depende da colaboração de cada um de nós para a conservação de recursos vitais. Explicou também que esse processo de conscientização pode parecer lento, mas é de extrema importância, já que a mudança de postura de cada um de nós pode desencadear uma corrente crescente de atitudes positivas com relação ao meio ambiente de forma geral, e nada melhor do que sermos exemplo dessas práticas.

Ao final desse encontro, foi possível notar uma inquietude em relação a certas atitudes erradas antes praticadas de modo comum, bem como a conscientização dos participantes quanto a essas práticas, o que nos leva a inferir que tal atividade deveria ser realizada com maior frequência nas escolas, visto que as mesmas causaram reflexões quanto ao comportamento diário com o lixo, podendo promover mudanças de hábito com respeito ao meio ambiente e a sua conservação.

\subsection{Sala de recursos: vídeo "Vamos cuidar do meio ambiente"}

No segundo dia de atividades, a turma piloto foi levada a assistir o vídeo "Vamos cuidar do meio ambiente". Nele, a "Turma da Mônica", do artista e desenhista Maurício de Souza, destaca a conservação do meio ambiente e falam sobre a regra dos 3R's: Reduzir, Reutilizar e Reciclar. Atualmente, são considerados 5R's: Repensar, Recusar, Reduzir, Reutilizar e Reciclar (GONÇALVES et al., 2016). Neste momento, a professora de Matemática, Bruna Moreira, fez uma abordagem sobre a temática em questão, buscando informações a respeito do conhecimento prévio dos alunos sobre o assunto a fim de incorporar vivências e trazer sentido às atividades matemáticas que seriam desenvolvidas posteriormente.

O vídeo com duração aproximada de vinte e cinco minutos conseguiu prender a atenção de todos, e foi possível notar uma comoção em relação ao fato relatado no vídeo sobre os animais marinhos, como golfinhos e tartarugas, que ao ingerirem o lixo industrial presente em seus habitats naturais, acabam por serem feridos ou mesmo vindos a morrer.

Outro momento marcante, foram os comentários sobre o Ribeirão do Chico Bento, um rio fictício, no qual o Chico Bento costumava pescar peixes e agora já não pode porque só consegue pescar lixo. Essa história é baseada nas boas lembranças da infância do autor Mauricio de Souza sobre a pesca nas águas do Rio Tietê em São Paulo (SOUZA, 1996). Um aluno relatou que seus avós, que viviam da pesca em Maricá, por diversas vezes recolhiam redes "recheadas com mais lixo do que peixe".

No momento que a personagem Mônica fala sobre o óleo de cozinha que é descartado na pia, indo parar em rios e mares, contribuindo com a poluição e provocando a morte dos peixes, um grupo de alunos moradores do bairro São José do Imbassaí, em Maricá, fizeram analogia com um fato que ocorreu em outubro de 2017, quando uma grande mortandade de peixes apareceu na lagoa do referido bairro. 
Sobre a regra dos 3R's apresentada pelo personagem Franjinha da turma da Mônica, alguns relataram que vivenciam algumas dessas atitudes em suas casas, como:

- Reduzir: o uso da energia elétrica, o consumo de sacolas plásticas e o tempo no banho.

- Reutilizar: as sucatas para fazer brinquedos, os copos de vidro de geleia, os potes de sorvete para armazenar feijão e o óleo de cozinha para fazer sabão.

- Reciclar: as latas, as garrafas PET e utilizar as cascas de legumes e frutas para adubar hortas.

Segundo Luiz et al. (2013, p. 117),

[...] uma das maneiras mais eficazes de contribuir para a preservação do meio ambiente é aderir no cotidiano ao Princípio dos 5R's, uma política que, além de tratar a questão da destinação dos resíduos sólidos, induz a uma reflexão crítica sobre o consumismo exagerado.

Ao término dessa etapa, foi visível a mudança de atitude dos participantes em relação ao lixo produzido por eles e ao redor deles.

Este período na sala de recursos durou cerca de cinquenta minutos.

\subsection{Sala de informática: pesquisas e "Jogo da Reciclagem"}

Após assistirem ao vídeo e aos debates que se seguiram, os participantes foram levados à sala de informática e orientados a pesquisar sobre os diversos tipos de lixo como, por exemplo, os materiais recicláveis e os danos causados pelo descarte inadequado de resíduos sólidos.

Durante essa etapa, algumas figuras foram destacadas. A Figura 3 mostra uma ave envolvida por uma sacola plástica na natureza.

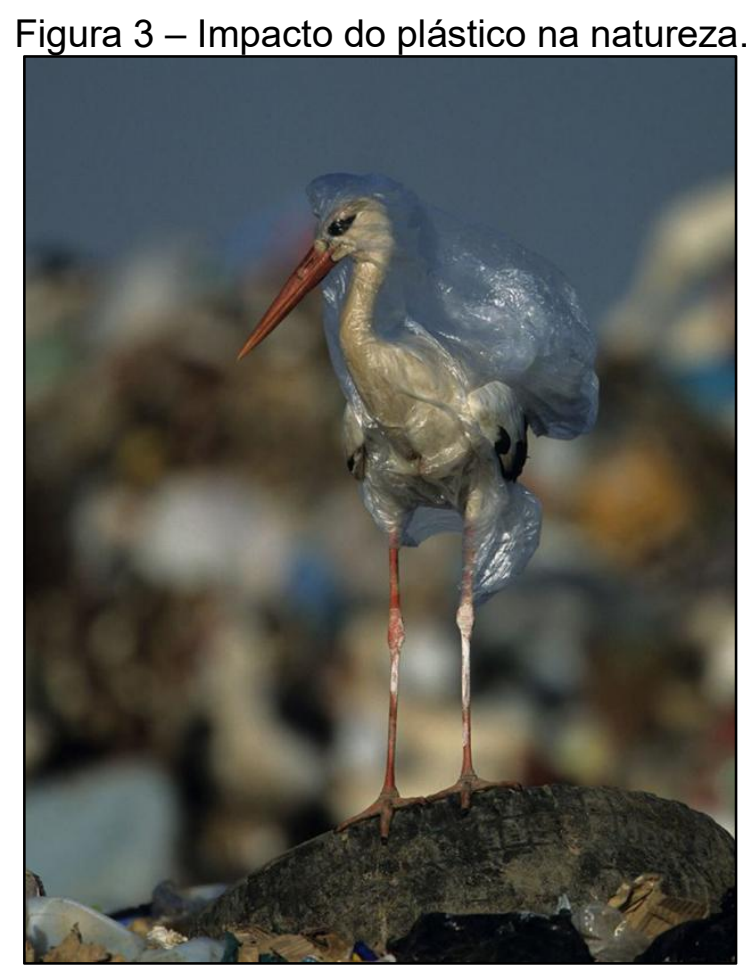

Fonte: Disponível em: http://www.aguasdepontal.com/2018/05/iniciativa-da-nat-geo-mostra-impactos.html. Acesso em: 7 ago. 2017. 
A Figura 4 apresenta, para um mesmo material, os tipos recicláveis e os não recicláveis. Erroneamente, os alunos haviam subentendido que todo vidro, plástico, papel e metal eram recicláveis.

Figura 4 - Tipos de materiais recicláveis e não recicláveis.

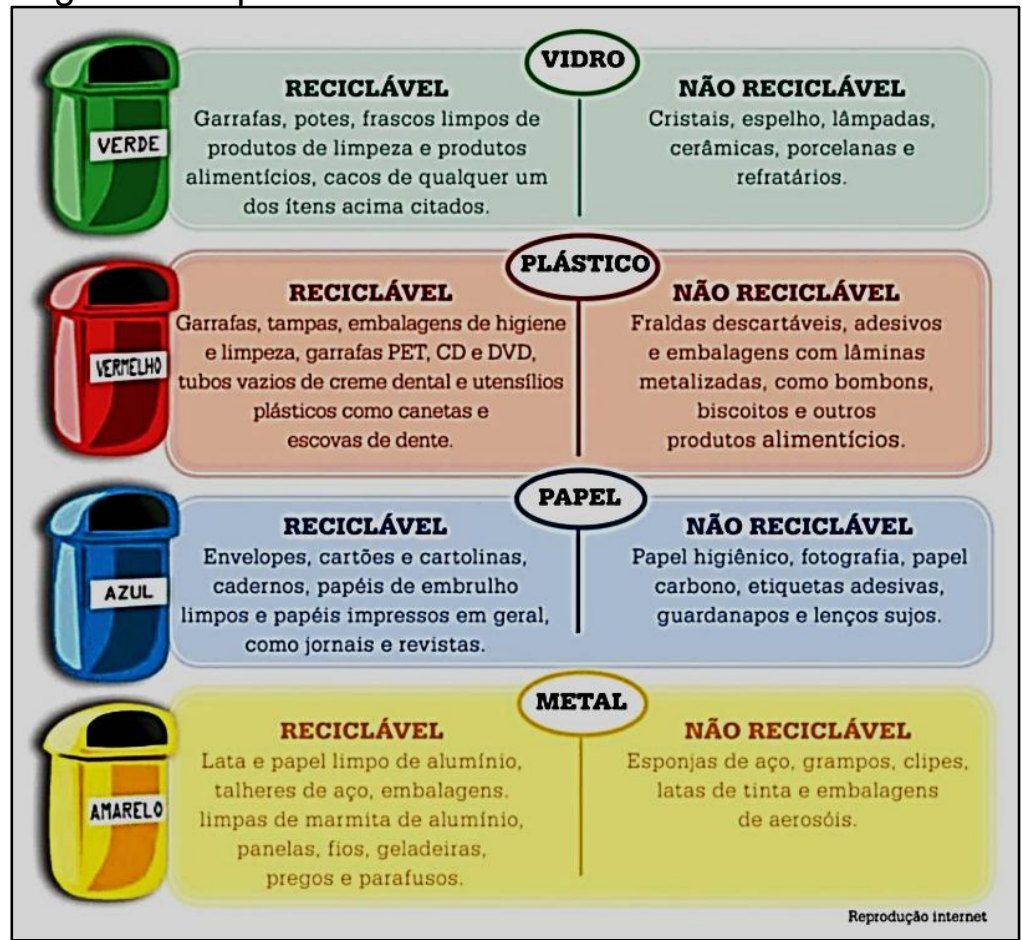

Fonte: Disponível em: http://chpdesigner.blogspot.com/2013/05/reciclar6.html. Acesso em: 7 ago. 2017.

A Figura 5 apresenta outras lixeiras para a coleta seletiva, além das convencionais. A lixeira destinada à madeira lhes causou grande curiosidade, levando-os a aprofundarem a pesquisa sobre o assunto. Assim, aprenderam que a madeira pode ser reutilizada na fabricação de papéis e celulose, além de poder ser triturada para o reuso na fabricação de placas aglomeradas que são utilizadas por indústrias de móveis e fabricantes de caixas e embalagens.

Figura 5 - Coleta seletiva.

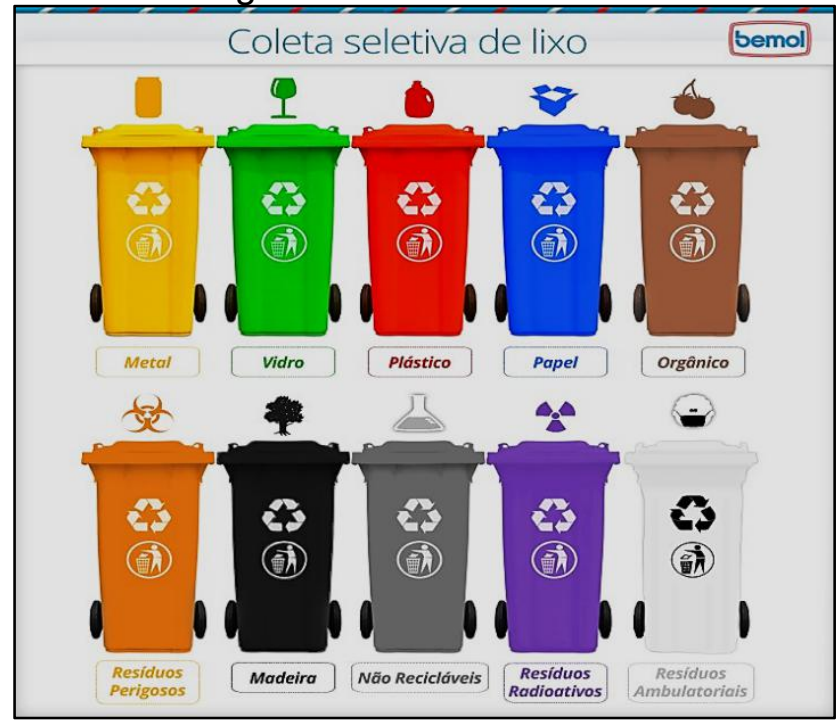

Fonte: Disponível em: http://blog.bemol.com.br/blog/2012/12/257/. Acesso em: 7 ago. 2017. 
Após a etapa das pesquisas sobre as principais lixeiras existentes, foi proposto o acesso ao site da TECHTUDO para jogarem o Jogo da Reciclagem, representado na Figura 6, desenvolvido pela Devworks Game Tecnology e lançado em treze de abril de 2010 (TECHTUDO, 2018). Este jogo, além de trabalhar a organização do lixo, trabalha a coordenação motora, a atenção, a concentração e o conceito de adição de números inteiros relativos, entre outras habilidades. Nessa atividade, o jogador precisa ajudar os condôminos a separarem corretamente o lixo reciclável nos compartimentos próprios de cada tipo. Usando o mouse para controlar a tampa do lixo, deixa-se passar apenas os lixos nas lixeiras corretas e rebatem-se os arremessos errados. Lixo no lugar certo ganha um ponto, lixo no lugar errado perde dois pontos.

Figura 6 - Jogo da Reciclagem.

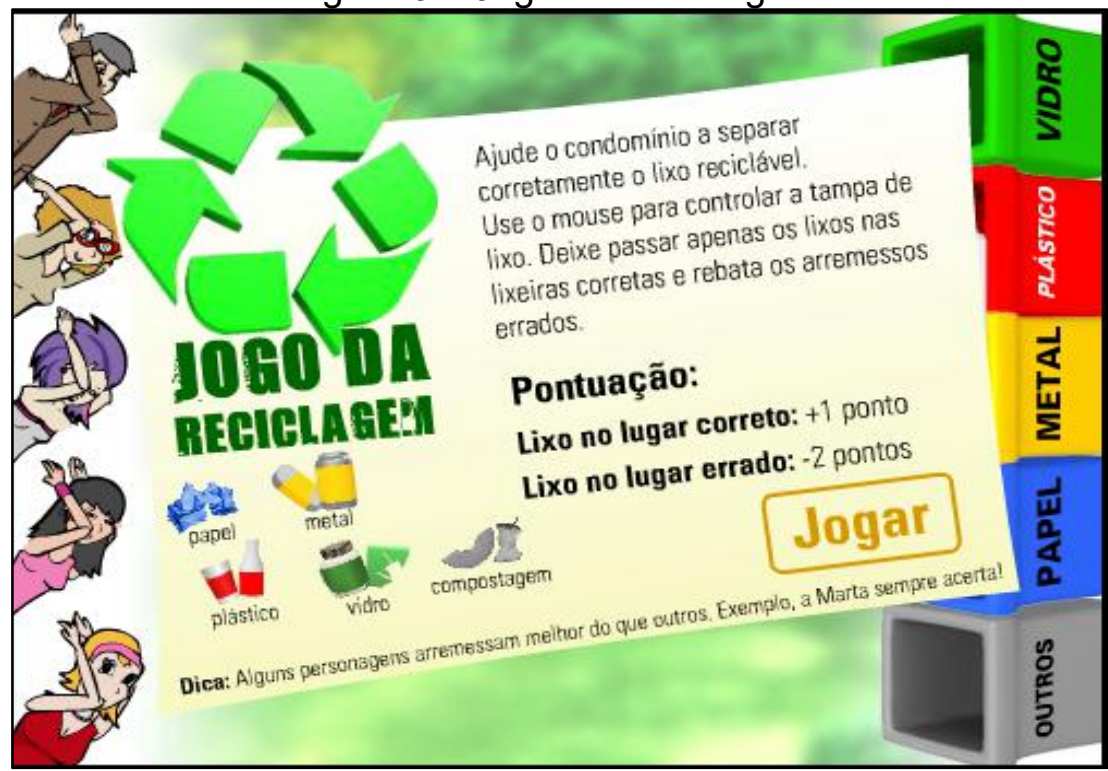

Fonte: Disponível em: https://www.techtudo.com.br/tudo-sobre/reciclagem.html. Acesso em: 7 ago. 2017.

Este jogo conseguiu tornar o conteúdo de operações com números relativos mais atraente e dinâmico. Conforme afirma Nascimento (2017, p. 95): "a aplicação de problemas matemáticos em forma de jogos tem oportunizado a conquista dos alunos, que podem ser atraídos por diversas formas de aprendizagem e interação".

Uma aluna se expressou dizendo que "nunca foi tão maneiro estudar Matemática e lixo" (sic). Isto reafirma o que ressaltam Smole, Diniz e Milani (2007, p. 10): “[...] todo jogo por natureza desafia, encanta, traz movimento, barulho e certa alegria para o espaço no qual normalmente entram apenas o livro, o caderno e o lápis".

Além da memorização das cores destinadas a cada tipo de lixo na reciclagem, foi possível notar que, a partir de certo momento, os alunos passaram a contabilizar sua pontuação rapidamente e em voz alta. Esta situação corrobora o que afirmam Pfiffer e Baier (2014, p. 6): “[...] os jogos auxiliam o estudante a superar seus próprios obstáculos, controlando seus pontos e os do seu adversário". Estas atividades na sala de informática tiveram a duração de uma hora e dez minutos. 


\subsection{Oficina de Artes e Matemática com reaproveitamento de materiais: transformando lixo em luxo!}

A proposta para a oficina de Artes e Matemática foi reaproveitar materiais recicláveis para a confecção de outros produtos, explorando formas geométricas e conceitos matemáticos em relação a medidas de massa, área e volume.

Para esta atividade, que foi realizada no terceiro dia, os alunos foram instruídos previamente a coletarem em suas casas os materiais recicláveis ou reutilizáveis como garrafas PET, potes de sorvete, garrafas de vidro, filtro de café usado e papel, os quais seriam utilizados na oficina. Os materiais coletados por cada grupo foram separados, classificados e pesados em balança para posterior aproveitamento destes dados na aula de Matemática. Além disso, ficou estabelecido que durante a prática fosse usado predominantemente o linguajar matemático com o objetivo de sua verbalização durante a prática pedagógica.

A oficina teve início com uma rodada de discussão sobre o desperdício de materiais, alimentos, vestuários e outros itens de consumo humano. A turma toda concordou que diversos produtos poderiam ser reutilizados antes de serem descartados, seja na sua função original ou criando novas formas de utilização, por exemplo, poderiam doar roupas que ficaram pequenas, levar sacolas retornáveis ao fazer compras, produzir húmus com os restos de material orgânico, entre outros.

Alguns alunos falaram que seus pais já tinham algumas práticas de reutilização de materiais, entre os quais citaram que: os potes de sorvete são utilizados para congelar feijão, as garrafas de vidro para armazenamento de água, as sacolas de plástico para ensacar lixo, as garrafas PET e caixas de papelão utilizadas para artesanato, entre outras finalidades semelhantes.

Para a confecção dos puxa-sacos, porta papel higiênico, porta trecos e caixas multiuso, foram utilizadas: garrafas PET, latas vazias de leite em pó, potes vazios de sorvete, garrafas vazias de vidro, caixas de sapato, filtros de café usados, materiais de papelaria (cola, tesoura, régua), assim como recortes e sobras de materiais que eventualmente seriam descartados. $\mathrm{A}$ confecção seguiu a ordem descrita abaixo.

1. Com as garrafas PET: o puxa saco e o porta papel higiênico representados na Figura 7.

2. Com as latas de leite: o porta trecos representado na Figura 8a.

3. Com os filtros de café: decoupage em caixas de papelão, conforme a Figura 8b.

4. Com os potes de sorvete: a caixa de costura representada na Figura 8c.

5. Com as garrafas de vidro: os vasos ornamentados com barbantes representados na Figura 9. 
Figura 7 - Confeccionando (a) puxa-saco e (b) porta papel higiênico com garrafas PET.

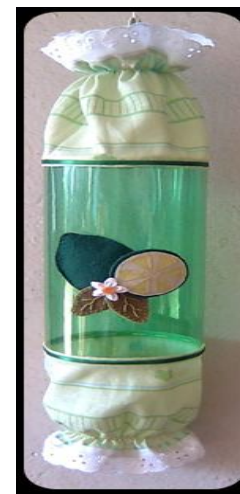

(a)

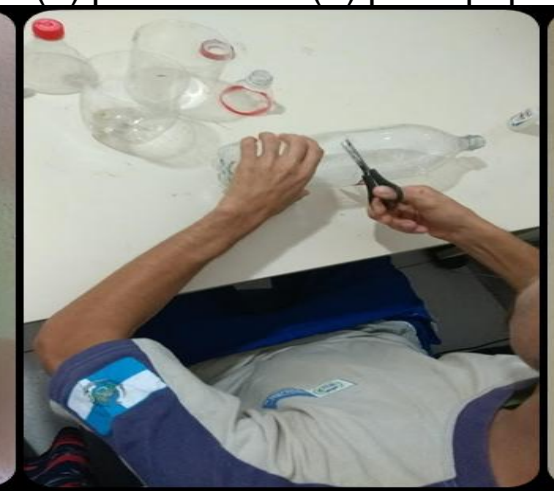

Fonte: Arquivo pessoal dos autores (2018).

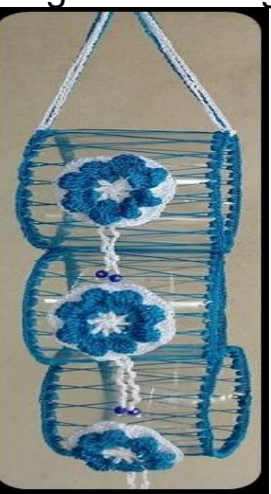

(b)

Figura 8 - Fazendo (a) porta-trecos com latas de leite, (b) decoupage com filtro de café, (c) caixa de costura com pote de sorvete.

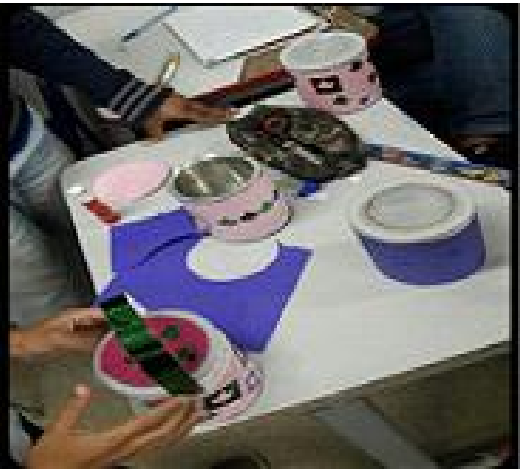

(a)

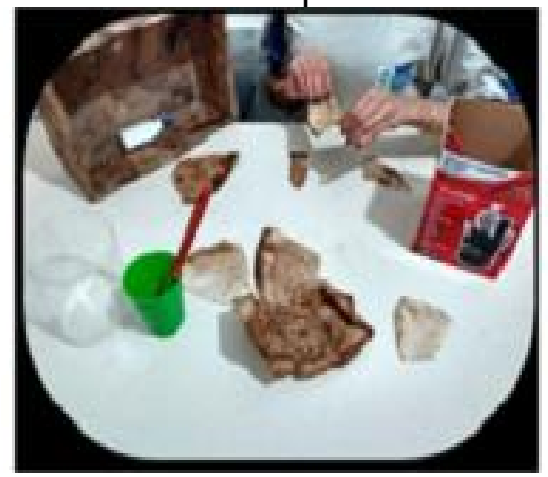

(b)

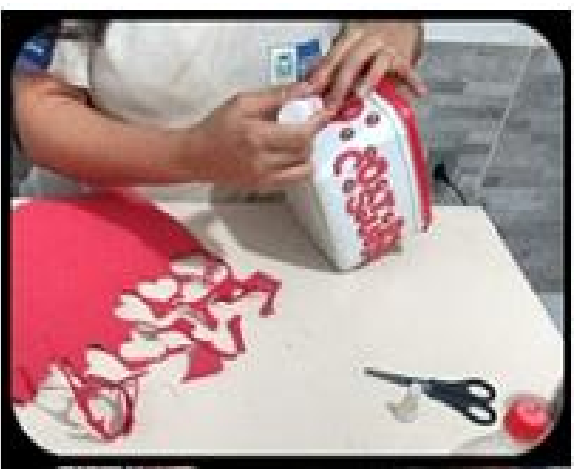

(c)

Fonte: Arquivo pessoal dos autores (2018).

Figura 9 - Confeccionando vasos ornamentais com garrafas de vidro.

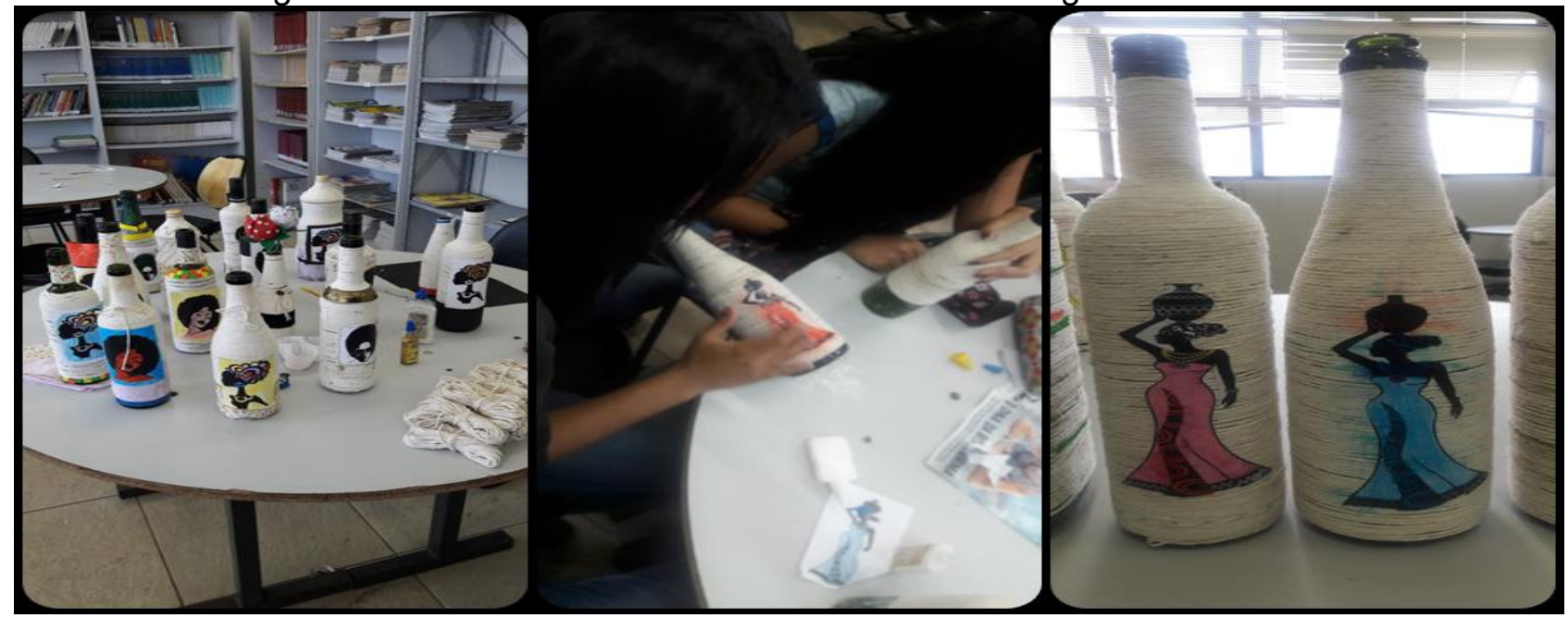

Fonte: Arquivo pessoal dos autores (2018).

Durante a produção desses objetos, os alunos mostraram-se interessados e participativos. Esta oficina conseguiu despertar a consciência para o reaproveitamento de materiais que antes eles não tinham. Uma das alunas disse que a partir de agora iria "pensar duas vezes antes de jogar qualquer coisa fora". Outro aluno relatou que isso já era prática em sua casa, pois seus pais 
trabalham com artesanato e reaproveitam muitas coisas, inclusive trouxe para a aula alguns artefatos feitos por sua mãe (porta papel higiênico e puxa saco).

Vale ressaltar que, constantemente, os alunos foram estimulados a usarem os conceitos matemáticos até então aprendidos em sala de aula, de modo a aplicá-los em cada passo da solução dos problemas propostos, bem como verbalizar os entes geométricos e as grandezas que foram objetos de estudo, como: "Pega pra mim este material de forma cilíndrica", "[...] a caixa cúbica?" "[...] não, a que tem formato de paralelepípedo", "[...] preciso de $50 \mathrm{~cm}$ do barbante, mas meio metro serve". O último exemplo foi "piada" de um aluno mais extrovertido.

Esta oficina possibilitou a reflexão sobre a ideia de que reutilizar um objeto é uma atitude positiva frente ao desperdício generalizado observado em pessoas consumistas. Além disso, foi possível observar a Matemática nos pequenos detalhes.

\subsection{Atividade de Matemática na sala de aula}

A atividade de Matemática deu-se no quarto dia, na sala de aula, com a turma piloto organizada em sete grupos.

Antes de confeccionar as utilidades domésticas, os participantes separaram, classificaram e pesaram os materiais coletados, o que permitiu a produção da Tabela 1 pelos próprios participantes.

Tabela 1 - Separação, classificação e pesagem do lixo coletado.

\begin{tabular}{cccccc}
\hline $\begin{array}{c}\text { Tipos de Lixo/ } \\
\text { Grupos }\end{array}$ & Plástico $(\boldsymbol{g})$ & Papel $(\boldsymbol{g})$ & Metal $(\boldsymbol{g})$ & Vidro $(\boldsymbol{g})$ & Total $(\boldsymbol{g})$ \\
\hline Grupo 1 & 420 & 200 & 200 & 800 & 1.620 \\
Grupo 2 & 680 & 400 & 350 & 700 & 2.130 \\
Grupo 3 & 280 & 150 & 100 & 550 & 1.080 \\
Grupo 4 & 350 & 120 & 400 & 100 & 970 \\
Grupo 5 & 500 & 340 & 150 & 1.200 & 2.190 \\
Grupo 6 & 150 & 410 & 500 & 280 & 1.340 \\
Grupo 7 & 450 & 100 & 450 & 630 & 1.630 \\
\hline Total (g) & $\mathbf{2 . 8 3 0}$ & $\mathbf{1 . 7 2 0}$ & $\mathbf{2 . 1 5 0}$ & $\mathbf{4 . 2 6 0}$ & $\mathbf{1 0 . 9 6 0}$ \\
\hline
\end{tabular}

Fonte: Elaboração dos autores (2018).

Este momento proporcionou lições matemáticas interessantes, bem como uma visão diferenciada sobre alguns materiais que são conhecidos como lixo.

Os participantes separaram o lixo por tipos, a saber: plástico, papel, metal e vidro. Depois dessa etapa, o lixo de cada tipo foi pesado usando uma balança comum, sendo os resultados registrados.

Assim, na aula de Matemática, os alunos foram convidados a criar problemas matemáticos usando os dados coletados. Surgiram questões como: 
1. Se em dois dias coletamos vinte garrafas PET, quantos dias são necessários para coletarmos mil garrafas PET?

Comentário: Por meio de Regra de Três Simples, obtiveram que seriam necessários 100 dias para coletarem mil garrafas PET.

2. O Grupo 3 coletou vinte garrafas de vidro. Se cada garrafa tem $250 \mathrm{~g}$ de massa, qual é a massa total das 20 garrafas?

Comentário: Por meio de uma simples multiplicação, seguida da transformação de gramas para quilogramas, obtiveram o resultado igual a $5 \mathrm{~kg}$.

3. Qual é a massa média de lixo coletado por grupo?

Comentário: Somando o total de lixo coletado por cada grupo e dividindo pela quantidade de grupos, obtiveram massa média igual aproximadamente 1,6 kg.

Este foi um momento muito interessante, pois criar problemas relacionados ao lixo coletado se tornou uma amigável competição.

Os seguintes problemas foram elaborados pela professora de Matemática e entregues aos grupos para que resolvessem:

1. Dentre os tipos de lixo recolhido, podemos afirmar que os que ocupavam maior espaço eram os mais pesados?

Comentário: Todos chegaram à conclusão de que não, pois os resíduos de plástico ocupavam o maior volume na sala, entretanto o lixo vítreo tinha a maior massa, conforme mostra o Gráfico 1. Assim, trabalhou-se as noções de medida de massa e de espaço.

Gráfico 1 - Representação da quantidade total de lixo coletado (em gramas).

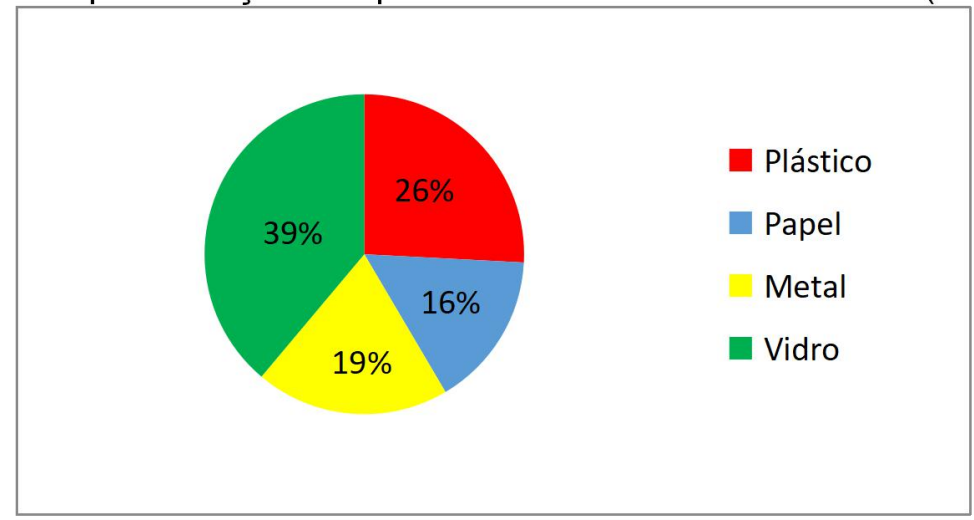

Fonte: Elaboração dos autores (2018).

2. Construa um Gráfico de Colunas representando a quantidade de plástico em gramas coletada pelos grupos e sua média aritmética.

Comentário: Os alunos entenderam o conceito de média aritmética simples definida por

$$
\text { Média }=\frac{x_{1}+x_{2}+x_{3}+\ldots+x_{n}}{n},
$$


onde $x_{1}, x_{2}, x_{3}, \ldots, x_{n}$ são números reais e $n$ é o número total de elementos do conjunto. Os participantes calcularam a média aritmética das quantidades de plástico levadas pelos grupos, encontrando assim o valor aproximado:

$$
\text { M édia }=\frac{420+680+280+350+500+150+450}{7} \cong \mathbf{4 0 4 , 2 8} \mathbf{g} \text {. }
$$

Em seguida foram orientados a representá-la como uma reta horizontal no gráfico de colunas, conforme mostra o Gráfico 2.

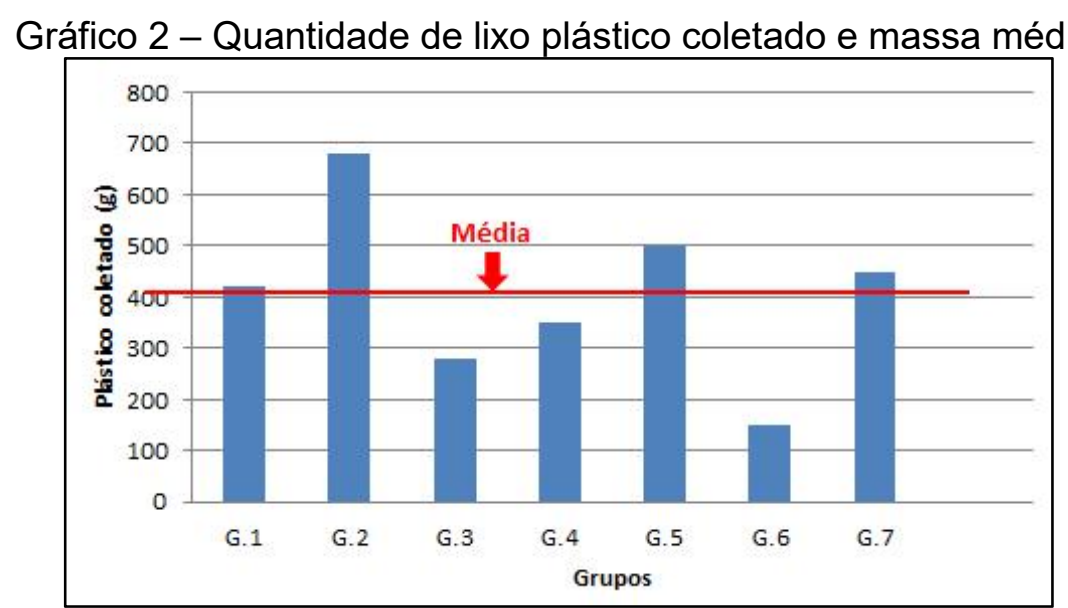

Fonte: Elaboração dos autores (2018).

Desta forma, foi trabalhada a média aritmética com os dados disponíveis.

Por meio da problemática trazida pelo Projeto "Praia Limpa é minha Praia" foi possível trabalhar conceitos de proporcionalidade e sistema métrico decimal, como:

1. Suponhamos que por meio do Projeto "Praia Limpa é minha Praia" foram recolhidos $50 \mathrm{~kg}$ de lixo na Lagoa de Maricá. Caso o Projeto fosse realizado mensalmente e a quantidade de lixo retirada se mantivesse constante, quantos quilos de lixo seriam recolhidos ao final de um ano?

Comentários: Trabalhou-se aqui o conceito de proporcionalidade. Multiplicando $50 \mathrm{~kg}$ por 12 (quantidade de meses que um ano possui) obtiveram $600 \mathrm{~kg}$ como resultado.

2. Durante a palestra da equipe do projeto "Praia Limpa é minha Praia" pode ser constatado que o material esfoliante utilizado em muitos sabonetes é o micro plástico. Considerando que a medida do micro plástico seja igual a $1 \mathrm{~mm}$, represente essa mesma medida em centímetros e em metros.

Comentário: Dividindo 1 por 10, obtiveram $0,1 \mathrm{~cm}$ e dividindo 1 por 1000 obtiveram 0,001 m. Assim, foi abordado o tema sistema métrico decimal.

Usando a lógica do "Jogo da Reciclagem" foi possível desenvolver problemas abordando números inteiros, como:

1. Em certo momento do jogo um aluno estava com -5 pontos. Então, deixou passar 5 lixos para as lixeiras corretas e 6 para as lixeiras erradas, e o jogo finalizou. Qual foi a pontuação deste aluno? 
Comentário: Considerando a lógica do jogo e utilizando operações básicas com números inteiros, os grupos chegaram à seguinte expressão numérica $-\mathbf{5}+\mathbf{1} \cdot(\mathbf{5})-$ $2 \cdot(6)$. Daí, solucionando-a como se segue: $-5+1 \cdot(5)-2 \cdot(6)=-5+5-12=$ $\mathbf{0}-\mathbf{1 2}=\mathbf{- 1 2}$, obtiveram como resultado 12 pontos. Com isso, foram trabalhados os conceitos de adição e multiplicação de números inteiros relativos.

2. Um jogador deixou passar 2 plásticos para a lixeira vermelha, 4 metais para a lixeira amarela, 5 vidros para a lixeira azul e 6 papeis para a lixeira cinza. Admitindo que não houve mais arremessos, qual foi a pontuação desse jogador?

Comentário: Considerando as cores corretas para cada tipo de lixo, temos 6 lixos arremessados na lixeira correta (2 plásticos na lixeira vermelha e 4 metais na lixeira amarela) e 11 arremessados na lixeira errada (5 vidros na lixeira azul (papel) e 6 papeis na lixeira cinza (outros)). Desta forma, chegou-se a expressão numérica: 1 . $(6)-2 \cdot(11)=6-22=-16$. Assim, concluiu-se que a pontuação do jogador foi -16 pontos. E, então, mais uma vez, trabalhou-se os conceitos de adição e multiplicação de números inteiros relativos.

A partir da propaganda de um cartaz da Waste Expo Brasil que dizia: "Nova regra: toda vez que você for à praia, colete ao menos 3 plásticos da areia" foi abordado o conceito de proporcionalidade e regra de três.

1. Considere que você e sua turma decidiram seguir a nova regra da Waste Expo Brasil. Sendo assim, em uma visita à lagoa de Maricá quantos plásticos no mínimo seriam coletados?

Comentário: Chamando de $x$ o número de plásticos coletados e considerando que a turma tinha 35 alunos, por meio de uma Regra de Três Simples, obtemos: $x=$ $(35)(3)=105$, chegando-se à conclusão de que seriam coletados, no mínimo, 105 plásticos.

2. Suponhamos que a cada 3 plásticos coletados, 2 peixes deixem de morrer. Considerando que cada pessoa colete exatamente 3 plásticos, quantas pessoas seriam necessárias para evitar a morte de 360 peixes?

Comentário: Considerando que cada pessoa coleta exatamente 3 plásticos, tem-se que 1 pessoa evitaria a morte de 2 peixes. Assim, denotando por $N$ a quantidade mínima de pessoas para a coleta de plásticos, a fim de se evitar a mortandade dos 360 peixes. Deste modo, utilizando-se de uma Regra de Três simples obtém-se: $x=\frac{(360)(3)}{2}=540$ plásticos e $N=\frac{540}{3}=180$ pessoas. Concluindo-se assim que são necessárias 180 pessoas para evitar a morte de 360 peixes.

Para finalizar, retomando a vivência na oficina "Transformando Lixo em Luxo!", foi possível trabalhar conceitos de sistema métrico decimal e noções de área. 
1. Durante a oficina "Transformando Lixo em Luxo!", suponha que foram utilizados $160 \mathrm{~cm}$ de barbante para decorar certa garrafa de vidro. Quantas garrafas como esta é possível decorar, sabendo que dispomos de $10 \mathrm{~m}$ de barbante?

Comentário: Transferindo a unidade de medida de metros para centímetros, encontrase $10 \mathrm{~m}=10000 \mathrm{~cm}$ e dividindo esse resultado por $160 \mathrm{~cm}$, obtém-se 62,5. Desse modo, alguns grupos concluíram que seria possível decorar 62 garrafas e outros consideraram que seriam 63 garrafas decoradas, visto que teria uma decorada pela metade.

2. Ainda em relação à oficina, suponhamos que na decoupage de 3 caixas foram utilizados 15 filtros de café. Se cada filtro tem aproximadamente $21 \mathrm{~cm}^{2}$ de área, qual a área coberta em cada caixa, aproximadamente?

Comentário: Por uma divisão simples, todos concluíram que, para cada caixa, foram utilizados 5 filtros. Daí, multiplicando por 21, obtiveram como resultado $105 \mathrm{~cm}^{2}$. E, assim, foi trabalhada a noção básica de área plana.

Em relação ao desempenho nestes problemas matemáticos propostos pela professora de Matemática, a maioria dos grupos teve um resultado satisfatório, com número de acertos maior ou igual à média de acertos por grupo (aproximadamente 8); entretanto o grupo 5 obteve um número de acertos inferior à média, como pode ser observado no Gráfico 3, mas este desenvolvimento abaixo da média pode ser atribuído a distrações em sala de aula, dificuldade de leitura e interpretação de texto.

Gráfico 3 - Representação do número de acertos por grupo das perguntas propostas.

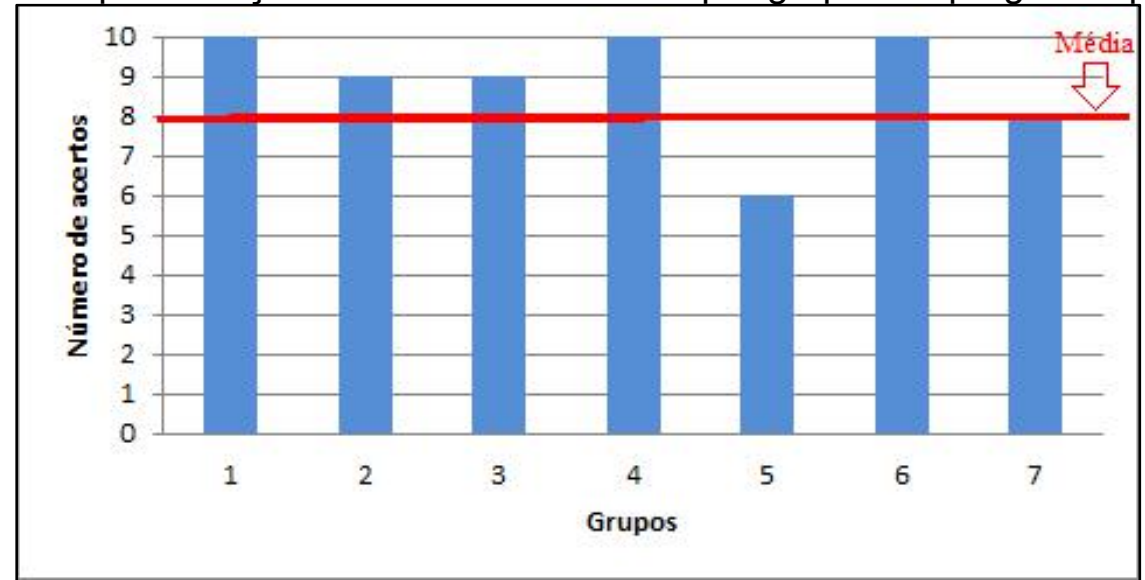

Fonte: Elaboração dos autores (2018).

Contudo, foi notório o desenvolvimento da maior parte dos grupos em relação à capacidade de refletir com autonomia acerca da compreensão de cada problema analisado. Isto é importante, pois o processo de ensino e aprendizagem em educação Matemática não se restringe a simples cálculos de fórmulas, mas sim capacitar o indivíduo por meio da Matemática e Ciências afins a refletir sobre como deve intervir, a pensar sobre suas intervenções e práticas de vida que impliquem em um menor impacto ambiental. 


\subsection{Produção textual}

O quinto e último dia de atividade se deu por meio de uma produção textual orientada pelo professor de Português, Edson Cavalcanti, com duração de cerca de cinquenta minutos.

A partir das redações individuais dos alunos envolvidos no projeto, pôde-se notar uma propensão à mudança de atitude e mentalidade dos mesmos para com alguns dos graves problemas ambientais decorrentes do consumo humano exagerado, tais como a não reutilização de materiais recicláveis e o descarte irregular de lixo em rios, lagoas e mares.

No decurso da produção textual, percebeu-se uma grande preocupação com a poluição, em particular na lagoa de Maricá, que é muito utilizada por pescadores da localidade. Igualmente, manifestaram suas preocupações com a "saúde" do planeta que ganharam força depois das atividades em que participaram.

Além disso, houve relatos sobre o fato de poderem usar a Matemática "da sala de aula", como média aritmética, construção de gráficos e unidade de medidas, em situações do cotidiano. As atividades mais comentadas foram o "Jogo da Reciclagem" e a oficina "Transformando Lixo em Luxo!".

O professor Edson ressaltou que, apesar de alguns erros de separação silábica, de gramática e de concordâncias, foi possível perceber que os alunos estavam motivados a escrever sobre o tema, redigindo seus respectivos textos com zelo e desenvoltura. Segue abaixo uma das produções textuais realizadas em sala (Figura 10).

Figura 10 - Produção textual de uma aluna, enunciado e transcrito.

\begin{tabular}{|c|c|}
\hline 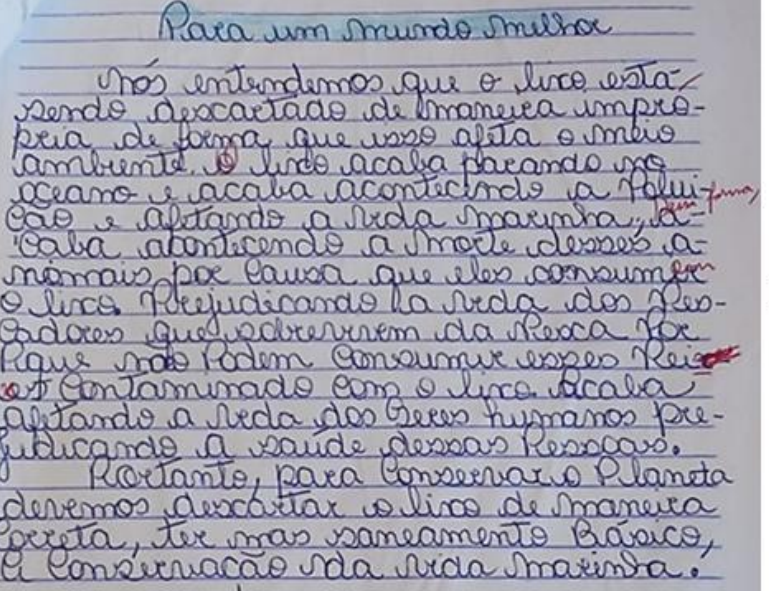 & $\begin{array}{l}\text { Para um mundo melhor } \\
\text { Nós entendemos que o lixo está sendo descartado de } \\
\text { maneira imprópria de forma que isso atrapalha o meio } \\
\text { ambiente. O lixo acaba parando no oceano e acaba } \\
\text { acontecendo a poluição e afetando a vida marinha, dessa } \\
\text { forma acaba acontecendo a morte desses animais por } \\
\text { causa que eles consomem o lixo. Prejudicando a vida dos } \\
\text { pescadores que sobrevivem da pesca porque não podem } \\
\text { consumir esses peixes contaminados com lixo. Acaba } \\
\text { afetando a vida dos seres humanos prejudicando a saúde } \\
\text { dessas pessoas. } \\
\text { Portanto, para conservar o planeta devemos } \\
\text { descartar o lixo de maneira correta, ter mais saneamento } \\
\text { básico, a conservação da vida marinha. }\end{array}$ \\
\hline
\end{tabular}

Fonte: Dados da pesquisa (2018).

\section{Considerações Finais}

Durante a realização das atividades descritas, foi possível notar o interesse de aproximadamente $90 \%$ do público alvo, assim como a real intenção de fazerem mudanças de atitudes para com o meio ambiente, como, por exemplo, o descarte e reaproveitamento de materiais. Além disso, de maneira geral, demonstraram ter entendido que a Matemática pode ser uma forte aliada à tomada de decisões e intervenções relacionadas a problemas ambientais, 
como nos resultados quantitativos e qualitativos de produção de lixo semanal em uma residência típica de uma cidade.

A expressiva participação dos alunos nas atividades realizadas nas oficinas de Matemática e Artes: "Transformando Lixo em Luxo!" demonstraram que o objetivo de despertar a consciência ecológica nos jovens participantes foi atingido; eles ficaram cientes e preocupados com o meio ambiente. Além disso, fixaram diversos conceitos de Matemática, tais como regra de três simples, média aritmética, sistemas de medidas e noções de estatística, por meio de problemas interdisciplinares.

Os participantes mostraram interesse pelo reaproveitamento de materiais, colaborando assim para a consciência de preservação do meio ambiente. Além disso, ficaram impactados ao quantificarem a massa total de lixo que deixaram de produzir por conta do reaproveitamento de materiais recicláveis.

Os alunos participantes do projeto estiveram envolvidos com a resolução de problemas oriundos da prática pedagógica voltada para a conscientização do meio ambiente e do descarte do lixo produzido. Um dos exemplos foi o uso de balanças proporcionando aos mesmos a experiência com unidades de medida de massa e capacidade, na qual, a partir dos dados coletados, puderam ser obtidas representações gráficas quantitativas sobre esses mesmos dados.

Participar dessas atividades tornou-se uma oportunidade ímpar para o desenvolvimento de um trabalho interdisciplinar envolvendo a Matemática como ferramenta para analisar problemas produzidos por questões ambientais. De fato, a interação e a colaboração dos alunos em cada etapa das atividades reafirmam o fato de que a interdisciplinaridade para a análise de questões como as que foram aqui trabalhadas colabora fortemente para a formação de alunos críticos, reflexivos e criativos, capazes de entenderem a importância da preservação do meio ambiente como um bem material intangível.

\section{Referências}

ARAÚJO, F.; SILVA, M.; CASTRO, R.; SALES, A.; PERES, F.; TIMBÓ, M. Projeto "Praia limpa é a minha praia": uma contribuição para a preservação dos ambientes aquáticos. Revista Interagir: pensando a extensão, Rio de Janeiro, n. 17/18/19, p. 81-89, 2014.

BRASIL. Secretaria de Educação Fundamental. Parâmetros Curriculares Nacionais: Matemática - Ensino de quinta à oitava série. Brasília: MEC/SEF, 1998.

ELLIOT, J. La investigación-acción en educación. Tradução de Pablo Manzano. 3. ed. Madrid: Morata, 1997.

GONÇALVES, F.; LEMES, D.; PROCHNOW, T.; DAL-FARRA, R. Problemáticas Ambientais: Conhecimentos e Concepções de Futuros Educadores e Comunidades. Revista de Ensino e Educação em Ciências Humanas, Londrina, v. 17, n. 1, p.13-18, 2016.

LUIZ, L. C.; RAU, K.; DE FREITAS, C. L.; PFITSCHER, E. D. Agenda Ambiental na Administração Pública (A3P) e práticas de sustentabilidade: estudo aplicado em um instituto federal de educação, 
ciência e tecnologia. Administração Pública e Gestão Social, Viçosa, v. 5, n. 2, p. 114-134, 2013.

NASCIMENTO, R. A. Uma compreensão matemática dos Jogos de Somatórios. REMAT: Revista Eletrônica da Matemática, Bento Gonçalves, v. 3, n. 1, p. 93-106, jul. 2017.

PFIFFER, C. S.; BAIER, T. Jogos para o estudo da matemática no ensino fundamental. Revista Dynamis, Blumenau, v. 20, n. 1, p. 3-16, 2014.

PONTE, J. P. O estudo de caso na investigação em educação matemática. Quadrante, v. 3, n. 1, p. 3-18, 1994.

SIQUEIRA, A. Práticas interdisciplinares na educação básica: uma revisão bibliográfica - 19702000. ETD - Educação Temática Digital, Campinas, v. 3, n.1, jul./dez. 2001. DOI: https://doi.org/10.20396/etd.v3i1.684.

SMOLE, K. C. S.; DINIZ, M. S. V.; MILANI, E. Jogos de matemática do $6^{\circ}$ ao $9^{\circ}$ ano. 1 . ed. Porto Alegre: Artmed, 2007.

SOUZA, Mauricio. Crônica: Revivendo Chico Bento. 19 nov. 1996. Disponível em: http://turmadamonica.uol.com.br/cronicas/revivendo-chico-bentol. Acesso em: 15 jan. 2019.

TAJRA, Sanmya Feitosa. Informática na educação. 7. ed. São Paulo: Érica, 2007.

TECHTUDO. Jogo da Reciclagem. Disponível em: https://www.techtudo.com.br/tudosobre/reciclagem.html. Acesso em: 01 ago. 2018. 